\title{
PENGARUH DISIPLIN KERJA DAN MOTIVASI TERHADAP KINERJA PEGAWAI DI PUSKESMAS MARANCAR UDIK KABUPATEN TAPANULI SELATAN
}

\section{Oleh:}

\section{Abdul Nasser Hasibuan; Rini Hayati Lubis; Arianti Winda Sari}

\section{Institut Agama Islam Negeri Padang Sidimpuan Jl. T. Rizal Nurdin Km. 4,5 Sihitang, Padang sidempuan}

\section{ABSTRAK}

Penelitian ini berkaitan dengan bidang ilmu manajemen sumber daya manusia dan ilmu sosial.Sehubungan dengan hal itu pendekatan yang dilakukan adalah teori-teori yang berkaitan dengan teori disiplin kerja, motivasi, dan kinerja pegawai/karyawan, dan beberapa teori yang diperlukan di dalam penelitian ini.

Penelitian ini merupakan penelitian kuantitatif.Sumber data yang digunakan adalah data primer.Teknik pengumpulan data yang digunakan adlah angket dan wawancara dengan jumlah sampel sebanyak 45 responden.Analisis yang digunakan adalah uji validitas, uji realibilitas, uji normalitas, uji linearitas, uji asumsi klasik, uji regresi linear berganda, uji koefisien determinasi $R^{2}$, uji parsial (uji t) dan uji koefisien regresi simultan (uji F).

Berdasalkan hasil analisis dengan menggunakan bantuan program SPSS Versi 23 maka diperoleh hasil pengukuran regresi dengan persamaan $\mathrm{Y}=9.429+0,750$ Disiplin + o,282 Motivasi dengan data Rsquare sebesar 0,985, berarti 98,5\% variabel disiplin dan motivasi mampu menerangkan variabel kinerja pegawai pada Kantor Puskesmas Marancar Udik Kabupaten Tapanuli Selatan, sedangkan sisanya sebesar 1,5\%, dipengaruhi oleh variabel lain. Hasil penelitian secara parsial (uji t) menyatakan bahwa, disiplin memiliki thitung $>$ ttabel(5.332 > 2,018), artinya disiplin kerja memiliki pengaruh signifikansi terhadap kinerja pegawai.Motivasi memiliki thitung $>t_{\text {tabel }}(12,043>2,018)$, artinya motivasi memiliki pengaruh signifikansi terhadap kinerja pegawai.Hasil penelitian secara Simultan (uji F) menyatakan bahwa disiplin kerja dan motivasi memiliki Fhitung $>F_{\text {tabel }}(132,188>0,282)$.Artinya Ho ditolak, maka dapat disimpulkan bahwa disiplin kerja dan motivasi secara besama-sama berpengaruh terhadap kinerja pegawai.

Kata Kunci: Disiplin kerja, Motivasi dan Kinerja pegawai. 


\section{ABSTRACT}

This research relates to the fields of human resource management and social sciences. In this connection the approach taken is theories related to the theory of work discipline, motivation, and employee / employee performance, and several theories needed in this study.

This research is a quantitative research. The data sources used are primary data. The data collection techniques used are questionnaires and interviews with a total sample of 45 respondents. The analysis used is validity test, reliability test, normality test, linearity test, classic assumption test, multiple linear regression test, test coefficient of determination R2, partial test ( $\mathrm{t}$ test) and simultaneous regression coefficient test (F test).

Based on the results of the analysis using the SPSS Version 23 program, the regression measurement results obtained with the equation $\mathrm{Y}=9,429+0,750$ Discipline + 0,282 Motivation with Rsquare data of 0,985, meaning 98.5\% discipline and motivation variables were able to explain employee performance variables at Marancar Public Health Office Udik, South Tapanuli Regency, while the remaining $1.5 \%$, is influenced by other variables. The results of the study partially ( $t$ test) states that, discipline has thitung $>\mathrm{t}$ table $(5,332>2,018)$, meaning that work discipline has a significant effect on employee performance. Motivation has tcount $>t$ table (12,043> 2,018), meaning motivation has a significant effect on performance Simultaneous research results (F test) state that work discipline and motivation have Fcount $>$ FtabeL $(132,188>0,282)$. The meaning of Ho is rejected, it can be concluded that work discipline and motivation jointly influence employee performance.

Keywords: Work discipline, motivation and employee performance. 


\section{PENDAHULUAN}

Sumber Daya Manusia adalah kemampuan terpadu dari daya piker dan daya fisik yang dimiliki individu. Perilaku dan sifatnya di tentukan oleh keturunan dan lingkungannya, sedangkan prestasi kerjanya dimotivasi oleh keinginan untuk memenuhi kepuasannya dan meningkatkan kinerjanya.

Kinerja pegawai merupakan hasil pekerjaan yang mempunyai hubungan kuat dengan tujuan strategis organisasi, kepuasan konsumen dan memberikan konstribusi ekonomi. Kepuasan konsumen dalam berobat ke Puskesmas Marancar Udik Kabupaten Tapanuli Selatan belum tercapai diamana hasil wawancara yang peneliti lakukan dengan ibu Lanniari Pasaribu yang mengatakan bahwa kebanyakan masyarakat lebih tertarik berobat ke bidan desa atau mantari daripada berobat ke puskesmas karena ibu tersebut melihat ketika beliau pergi berobat ke puskesmas pada pagi hari jam o8.30 pegawainya belum ada. Dari wawancara ibu Lanniari Pasaribu tersebut dapat disimpulkan bahwa pegawai puskesmas tidak disiplin. Karena tidk hadir dengan tepat waktu dari jam kerja yang ditetapkan oleh organisasi.

Kemudian wawancara selanjutnya dengan Bapak Arjuni Gultom dari Desa Sugi Kec. Marancar selaku sebagai pengunjung yang pernah berobat ke puskesmas marancar tersebut mengatakan bahwa berobat ke bidan jauh lebih cepat dan tidak memakan waktu yang lama karena bapak tersebut mengatakan kalau ia sering berobat pada pagi hari. Karena penyakitnya sering kambuh di pagi hari, sementara bapak tersebut haus pergi cepat bekerja di pagi hari, jika bapak Arjuni Gultom berobat ke puskesmas maka akan memakan waktu dikarenakan pegawainya tidak ada, lokasinya yang jauh dari rumahnya. Dari wawancara Bapak Arjuni Gultom dapat disimpulkan bahwa motivasi pegawai menurun karena tidak ada rasa tanggung jawab dan solidaritas terhadap pekerjaan dan pengunjung yang berobat ke puskesmas tersebut.

Wawancara yang terahir peneliti lakukan dengan Ibu Nurhanim Pospos pengunjung dari desa Poken Arba Ibu tersebut mengatakan bahwa ia lebih sering berobat kebidan desa atau mantari yang lewat dan datang ke Desa Ibu tersebut karena Ibu tersebut mengatatakan kalau berobat ke puskesms obatnya tidak lengkap dan dokternya jarang datang. Dan berobat ke mantari jauh lebih cepat dan tepat. Dari wawancara Ibu Nurhanim pospos tersebut dapat disimpulkan bahwa kinerja pegawai menurun hal itu dikarenakan pegawai tidak memiliki kemampuan dalam memberikan obat yang pas untuk pengunjung sehingga pengunjung lebih tertarik 
berobat ke mantari atau bidan desa yang menurut pengunjung lebih aman dan lebih cepat.

Dari hasil wawancara diatas yang peneliti lakukan terlihat bahwa pegawai sering tidak hadir dari jam masuk yang ditentukan, ini menandakan pegawai yang tidak disiplin, tidak termotivasi dalam bekerja sehingga kinerja pegawai menurun. Untuk meningkatkan dan mencapai semua tujuan maka setiap orang harus memiliki kedisiplinan yang tinggi. Irham Fahmi mengatakan dalam bukunya yang berjudul Manajemen Sumber Daya Manusia teori dan aplikasi bahwa " membangun kedisiplinan yang tinggi dibutuhkan motivasi yang tinggi “, motivasi boleh disebut sebagai sprit atau semangat, maka kedisiplinan merupakan semangat untuk menjadi lebih baik, jika motivasi dan disiplin meningkat maka kinerja akan semakin baik. Dari teori diatas dapat disimpulkan bahwa disiplin suatu pegawai dapat terwujud apabila adanya motivasi pegawai dalam bekerja sebaliknya jika pegawai menerapkan disiplin yang kuat di dalam suatu organisasi tersebut maka motivasi kerja pegwai akan meningkat dan apabila disiplin dan motivsi berjalan dengan baik maka kinerja akan membaik. Jumlah pegawai di Puskesmas Marancar Udik Kabupaten Tapanuli Selatan berjumlah 45 pegawai. Tingkat kehadiran merupakan indikator umum yang dapat mencerminkan kurangnya suatu disiplin karyawan atau pegawai dalam suatu organisasi.

Dari hasil wawancara yang peneliti lakukan dengan Yusniar Hasibuan STr. Keb selaku penanggung jawab administrasi umum Puskesmas Marancar Udik, bahwa Pada Puskesmas Marancar Udik Kabupaten Tapanuli Selatan tingkat absensi kehadiran yang harus ditaati minimal sebesar 80 persen.Akan tetapi tingkat absensi 80 persen ini merupakan salah satu indikasi adanya masalah dalam Puskesmas Marancar Udik, maka perlu mendapat perhatian serius dari pihak manajemen organisasi karena tingkat absensi merupakan suatu indikator kurangnya disiplin karyawan.

Disiplin yang baik mencerminkan besarnya rasa tanggung jawab seseorang terhadap tugas-tugas yang diberikan kepadanya. Hal ini mendorong gairah kerja, semangat kerja, dan terwujudnya tujuan perusahaan, karyawan dan masyarakat. Oleh karena itu setiap pimpinan selalu berusaha agar bawahannya mempunyai disiplin yang baik. Seorang pimpinan dikatakan efektif dalam kepemimpinanya, jika para bawahannya berdisiplin baik. Untuk memelihara dan meningkatkan 
kedisiplinan yang baik adalah hal yang sulit, karena banyak faktor yang memengaruhinya.

Disiplin dapat dikembangkan melalui suatu latihan antara lain dengan bekerja menghargai waktu tenaga dan biaya. Adapun tingkat kehadiran pegawai pada Puskesmas Marancar Udik Kabupaten Tapanuli Selatan terlihat pada tabel sebagai berikut:

Tabel 1.1

Rekapitulasi Absensi Pegawai Puskesmas Marancar udik Kabupaten Tapanuli Selatan periode bulan Agustus-Desember 2017.

\begin{tabular}{|c|c|c|c|c|c|c|}
\hline No & Bulan & $\begin{array}{c}\text { Jumlah } \\
\text { Pegawai }\end{array}$ & Sakit & Izin & tanpa Keterangn & \% \\
\hline 1 & Agustus & 45 & 11 & 10 & 15 & $45 \%$ \\
\hline 2 & September & 45 & 15 & 15 & 24 & $70 \%$ \\
\hline 3 & Oktober & 45 & 11 & 12 & 25 & $60 \%$ \\
\hline 4 & November & 45 & 10 & 13 & 26 & $64 \%$ \\
\hline 5 & Desember & 45 & 14 & 16 & 23 & $65 \%$ \\
\hline \multicolumn{7}{|r|}{ Mentukan persentase kehadiran pegawaijumlah tidak hadir/jumlah pegawai+ } \\
hari kerjax 100\%
\end{tabular}

Sumber : Puskesmas Marancar Udik Kabupaten Tapanuli Selatan.

Dari tabel 1.1 dapat disimpulkan bahwa tingkat kehadiran tanpa keterangan selalu meningkat yang tertinggi terletak pada bulan September sebesar 70\%. Ini menandakan bahwa absensi berpengaruh pada tingkat kedisiplinan pegawai dan motivasi kerja pegawai. Hal ini terlihat dari wawancara yang peneliti lakukan dengan karmila Sormin Am.Keb selaku Staf Puskesmas Marancar Udik, bahwa tingkat keterlambatan pegawai saat masuk kerja lebih awal dari yang seharusnya dan tidak mengikuti apel pagi, peningkatan ketidakhadiran pegawai tanpa alasan tersebut dikarenakan kurangnya pengawasan dan perhatian pimpinan terhadap pegawainya sehingga tidak termotivasi untuk bekerja secara maksimal. Kurangnya keinginan dan kesadaran untuk mentaati peraturan instansi pemerintah dan norma-norma sosial.

Sehingga pekerjan karyawan tidak dapat terselesaikan sesuai dengan yang direncanakan kemudian wawancara berikutnya yg peneliti lakukan pada pegawai Puskesmas. Marancar Udik Kabupaten Tapanuli Selatan Elfida Nora Harahap Am.Keb selaku pegawai Puskesmas Marancar Udik, bahwa masih banyak pegawai yang terlambat masuk kerja sehingga tidak dapat mengikuti apel pagi dan masih ada pegawai yang pulang lebih cepat dari yang seharusnya ditentukan pada jam kerja. Berdasarkan hasil wawancara tersebut keterlambatan pegawai saat masuk kerja itu 
disebabkan oleh beberapa alasan yaitu : Rumah yang jauh dengan lokasi kerja, dan alasan beberapa pegawai pulang lebih cepat dikarenakan oleh adanya keperluan pribadi. Pegawai harus disiplin pada peraturan-peraturan yang berlaku, dirinya, dan tugas-tugasnya.

Dengan demikian kualitas sumber daya manusia diharapkan dapat meningkatkan motivasi kerja pegawai. Menurut Muchdarsyah Sinungan Motivasi adalah keadaan kejiwaan dan sikap mental manusia yang memberikan energi, mendorong kegiatan atau gerakan dan mengarah atau menyalurkan perilaku kearah mencapai kebutuhan yang memberi kepuasan atau mengurangi ketidakseimbangan. Kebutuhan-kebutuhan tersebut timbul akibat dari hubungan antar manusia yang dalam hal ini lebih ditekankan pada hubungan yang terjadi di dalam proses produksi yaitu hubungan industrial. Oleh kerena itu motivasi dapat diartikan sebagai bagian integral dari hubungan industrial dalam rangka proses pembinaan, pengembangan dan pengarahan sumber daya manusia dalam suatu perusahaan.

\section{TINJAUAN TEORITIK}

\section{A. Kinerja Pegawai}

Kinerja adalah bagaimana seseorang diharapkan dapat berfungsi dan berperilaku sesuai dengan tugas yang telah dibebankan kepadanya. Pada umumnya kinerja diberi batasan sebagai kesuksesan seseorang di dalam melaksanakan suatu pekerjaan. Suatu organisasi, baik organisasi fundamental maupun privat dalam mencapai tujuan yang ditetapkan harus melalui sarana dalam bentuk organisasi yang digerakkan oleh sekelompok orang yang berperan aktif sebagai pelaku (actors) dalam upaya $m$ encapai tujuan lembaga atau organisasi yang bersangkutan. Pengertian kinerja menurut Henry Simamora bahwa kinerja karyawan merupakan tingkat dimana para karyawan mencapai persyaratan- persyaratan pekerjaan. Gary Deseller mengatakan kinerja hamper sama dengan perestasi kerja ialah perbandingan antara hasil kerja actual dengan standar kerja yang ditetapkan, dalam hal ini kinerja lebih memfokuskan pada hasil kerja. Dari pengertian kinerja diatas dapat dikatakan bahwa kinerja adalah suatu hasil yang diperoleh seseorang dari kerja yang telah ia selesaikan dan tercapainya harapan dan tujuan organisasi yang diharapkan. Penilaian kinerja mengacu pada suatu system formal dan terstruktur yang digunakan untuk mengukur, menilai, dan memengaruhi sifat-sifat yang berkaitan dengan pekerjaan, perilaku dan hasil termasuk tingkat kehadiran. Dengan 
demikian penilaian kinerja merupakan hasil kerja karyawan dalam lingkup tanggung jawabnya.

\section{B. Disiplin Kerja}

Disiplin merupakan tindakan manajemen untuk mendorong para anggota organisasi memenuhi tuntutan berbagai ketentuan bermotivasi tersebut. dengan demikian, pendisiplinan pegawai adalah suatu bentuk pelatihan yang berusaha memperbaiki dan membentuk pengetahuan, sikap dan perilaku pegawai sehingga para pegawai tersebut secara suka rela berusaha bekerja secara koperatif dengan para pegawai yang lain serta meningkatkan prestasi kerjanya. Disiplin kerja dalam perspektif islam adalah suatu ibadah, yang dilakukan seseorang dangan rasa tulus ikhlas, taat, mengikuti. Segi-segi agama yang telah dihayati dalam hati seseorang tersebut diwujudkan dalam bentuk penghayatan dan pengalman terhadap ajaran agama yang tercermin dalam perillaku dan sikap terhadap kedisiplinan. Dengan kata lain disiplin adalah sikap menaati peraturan dan ketentuan yang telah ditetapkannya pamrih. Sebagaimana firman allah dalam surah As-Shaf : 4 .

\section{MOTIVASI}

Motivasi (motivation) sebagai proses yang menjelaskan intensi arah, dan ketekun seorang individu untuk mencapai tujuannya.Intensitas yang berhubungan dengan seberapa giat seseorang berusaha, intensitas yang tinggi sepertinya tidak akan menhasilkan prestasi kerja yang memuaskan kecuali upaya tersebut dikaitkan dengan arah yang menguntungkan organisasi/instansi. Ketekunan disini memiliki dimensi yang merupakan ukuran mengenai beberapa lama seseorang bisa mempertahankan usahamya. Motivasi merupakan fenomena yang banyak corak dan ragamnya. Secara umum motivasi dapat diklasifikasikan ke dalam empat jenis yang satu sama lain memberi warna terhadap aktivitas manusia. Motivasi yang dimaksudkan disini tidak terlepas dari konteks manusia organisasional. Islam mengajarkan pada ummatnya agar tidak bersikap lemah, selalu bersemangat dan lebih mandiri menyikapi sesuatu yang berhubungan dengan diri sendiri.

\section{METEDOLOGI PENELTIAN}

Jenis penelitian yang digunakan oleh peneliti adalah penelitian kuantitatif dengan pendekatan diksriptif.Penelitian dengan pendekatan kuantitatif menekankan analisisnya pada data-data numerical (angka) yang diolah dengan metode statistika. 
Dalam penelitian ini, populasi yang dimaksud adalah seluruh karyawan pada Puskesmas Marancar yang berjumlah 45 pegawai. Sampel dalam penelitian ini adalah seluruh pegawai Puskesmas Marancar Udik Kabupaten Tapanuli Selatan yang berjumlah 45 responden. Data yang digunakan dalam melaksanakan penelitian ini adalah data primer, langsung melalui responden melalui kuisoner di samping itu juga melakukan wawancara dengan pegawai di Puskesmas Marancar UdikKabupaten Tapanuli Selatan. Data primer adalah data yang dipeoleh langsung dari subjek penelitian dengan mengenakan alat pengukuran atau alat pengambilan data langsung pada subjek sebagai sumber informasi yang dicari. Data sekunder dalam penelitian ini adalah berwujud data dokumentasi atau data laporan yang telah tersedia yang berasal dari kantor Puskesmas Marancar Udik Kabupaten Tapanuli Selatan. Sebagian besar penelitian umumnya menggunakan kuesioner sebagaai metode yang dipilih untuk mengumpulkan data.kuesioner atau angket.

\section{HASIL PENELITIAN}

Dari pengujian hipotesis di atas dapat diketahui bahwa Pengaruh disiplin kerja terhadap kinerja pegawai dari hasil analisis regresi yang dilakukan secara parsial disiplin kerja mempunyai pengaruh terhadap kinerja pegawai dengan nilai $t_{\text {hitumg }}>t_{\text {tabel }}$ yaitu 5,332 $>$ o,2018. Maka Ha diterima Ho ditolak. Jadi, dapat disimpulkan bahwa terdapat pengaruh disiplin kerja dan motivasi terhadap kinerja pegawai di Puskesmas Marancar Udik Kabupaten Tapnuli Selatan. Jika variabel disiplin kerja dan motivasi meningkat maka kinerja pegawai juga bakan meningkat. Hasil penelitian ini sejalan dengan penelitian yang dilakukan Ahmad Musliman, pengaruhInsentif dan Motivasi Terhadap Kinerja (tudi kasus PT. Aksara Putri Palembang) yang menyatakan baha insentif dan disiplin pegawai berpengaruh terhadap kinerja pegawai. Dilihat dari uji hipotesis menunjukkan $t_{\text {hitumg }}>t_{\text {tabe }}$ yaitu : 3,061 > 1,701. Maka dapat disimpulkan bahwa variabel insentif dan disiplin pegawai berpengaruh terhadap kinerja pegawai (studi kasus PT. Aksara Palembang) . Jadi kesimpulannya, disiplin kerja dan motivasi berpengaruh terhadap kinerja pegawai di puskesmas Marancar Udik Kabupaten Tapanuli Selatan. Sehingga organisasi diharapkan untuk bersikap tegas terhadap peraturan-peraturan yang ada dalam perusahaan guna untuk mendidik disiplin para pegawai dalam memberikan kinerja 
yang baik di dalam organisasi, serta mmeberikan dorongan kepada para pegawai agar dapat mencapai tujuan suatu organisasi yang baik.

Hasil pengaruh Motivasi Terhadap Kinerja Pegawai. Dari hasil analisis regresi yang dilakukan dapat diketahui baha displin kerja dan motivasi berpengaruh terhdap kinerja pegawai dengan menggunakan uji t pada tingkat signifikansi $5 \%$ (o,005), maka diperoleh hasil $t_{\text {hitung }} 12,043$. Hal ini menunjukkan bahwa ada pengaruh disiplin kerja dan motivasi terhadap kinerjanpegawai di puskesmas marancar udik kabupaten tapanuli selatan yang dilihat dari nilai $t_{\text {hitum }}>t_{\text {taba }} 12,043>0,2018$. Hasil pene;itian ini sejalan dengan penelitian Ratna Wijayanti dengan judul Pengaruh Kediplinan dan intensif Terhadap Kinerja (Y) hal ini ditujukan dari hasil uji t yang nilai koefisiennya 7,565, 5,414, dan 2.345. lebih bsar engan ttabel sebesar 1,658 mka thitung ditolak (Ho). Artinya seluruh hiptesis yang disjukan dalam penelitian ini memiliki pengaruh terhadap Kinerja (Y). Maka dapat disimpulkan bahwa disiplin dan motivasi sangat diperlukan untuk menunjang aktivitas organisasi agar tujuan dapat tercapai secara maksimal.

Dari hasil analisis regresi yang dilakukan dalam penelitian ini diketahui fhitung . ftabel (1329,188 > 3,220 ) maka Ha diterima hal ini menunjukkan ada pengaruh disiplin kerja dan motivasi terhadapkinerja pegawai di kantor \{usksmas Marancar Udik Kabupaten Tapanuli Selatan secara simultan. Maka dapat disimpulkan bahwa terdapat pengaruh antara disiplin kerja dan motivasi secara bersama-sama (simultan) terhadap kinerja pegawai di Puskesmas Marancar Udik kabupaten Tapanuli Selatan, baha disiplin an motivasi sangat diperlukan untuk menunjang kelancaran segala aktivitas organisasi agar tujuan organisasi dapat tercapai secara maksimal.

Dari hasil analisis regresi yang dilakukan peneliti diperoleh angka nilai $\mathrm{R}$ sebear 0,992. Nilai R sebesar 0,992, menunjukkan hubungan antara variable independen (Disiplin Kerja dan Motivasi) terhadap variabel dependen (Kinerja Pegawai) berada pada kategori sangat kuat seauai dengan kategori pada table 3.5 yang menjelaskan bahwa nilai $\mathrm{R}$ berada diantara 0,80 - 1,000 $(0,992)$, hal ini menunjukkan bahwa variabel independen dan dependen memiliki hubungan yang sangat kuat.

Sedangkan nilai $R$ Square sebesar 0,985 , hal ini menunjukkan bahwa persentase pengaruh disiplin dan motivasi terhadap kinerja pegawai sebesar $98,5 \%$. 
Sedangkan sisanya sebesar $1,5 \%$ dipengaruhi oleh variabel lain yang tidak dimasukkan dalam model penelitian ini.

\section{KESIMPULAN}

Berdasarkan hasil penelitian dengan nilai $\mathrm{R}_{2}(R$ Square) sebesar 0,985 yang dilakukan peneliti dengan judul "Pengaruh Disiplin Kerja dan Motivasi Terhadap Kinerja Pegawai di Puskesmas Marancar Udik Kabupaten Tapanuli Selatan” maka dapat disimpulkan sebagai berikut : Ada pengaruh disiplin kerja terhadap kinerja pegawai, yang dibuktikan melalui uji parsial dengan melihat nilai $t_{\text {hitung }}$ disiplin kerja $5,332>t_{\text {tabel }}$ senilai 0,2018. Ada pengaruh motivasi terhadap kinerja pegawai, yang dibuktikan melalui uji parsial dengan melihat nilai $t_{\text {hitung }}$ motivasi senilai 12,043 $>t_{\text {tabel }}$ senilai 0,2018. Terdapat pengaruh disiplin kerja dan motivasi secara parsial dan simultan terhadap kinerja pegawai di Puskesmas Marancarudik Kabupaten Tapanuli Selatan yang dibuktikan dengan melihat nilai uji simultan $\mathrm{F}$ dengan nilai $\mathrm{F}_{\text {hitung }}$ sebesar 1329,18 .

\section{DAFTAR PUSTAKA}

Amini, perilaku OrganisasiBandung: CitaPustaka Media, 2004.

BambangPrasetyo, MetodePeneltianKuantitatifJakarta: PT Raja GrafindoPersada, 2005.

BurhanBungin, MetodologiPenelitianKuantitatif, Jakarta: Kencana, 2006, hlm. 123 .

DepartemenAgama , Al-qur'andanterjemahannyaJakarta : Toha Putra, 2005.

Departemen Agama, Al-qur'andanterjemahannyaJakarta, TarmijiTaher, 1995 .

Duwipriyatno ,SPSS 22: Pengolahan Data Terpraktis,Yogyakarta: Andi Offset, 2014.

DwiSuwiknyo, Ayat-AyatEkonomi IslamYogyakarta :PustakaPelajar, 2010.

EdySutrisno, BudayaOrganisasi,Jakarta :KencanaPrenada Media Group,2010.

Gary Desseler, ManajemenSumberDayaManusia Jakarta: PT. Indeks, 2007.

WawancarabersamaBapakArjuniGultom, PengunjungPuskesmasMarancarUdik, 25 Mei 2018 pkl. o8.30. 
WawancarabersamaElfida Nora HarahappegawaiPuskesmasnMarancarUdik, 24 November 2017 pkl. 14.12.

WawancarabersamaIbuLanniariPasaribuPengunjungPuskesmasMarancarUdi k, 24Mei 2018 pkl. 09.30 Wib.

Wawancara bersama Ibu Nurhanimpospos ,PengunjungPuskesmasMarancarUdik, 26 mei 2018 pkl. 15.0o Wib.

WawancarabersamaibuYusniarHasibuan,

BendaharaPuskesmasMarancarUdik 22 November 2017, Pkl. 11.oo Wib.

WawancarabersamaKarmilaSormin,

StafAdministrasiPuskesmasMarancarUdik, 23 November 2017 pkl. 11.00

Henry Simamora, ManajemenSumberDayaManusiaYogyakarta :Libery,1997

Husein Umar, MetodePenelitianUntukSkripsidanTesisBisnis, (Jakarta: PT Raja GrafindoPersada, 2013.

Iqbalhasan, analisis data penelitiandengan statistic,Jakarta: BumiAksara, 2006

IrhamFahmi, ManajemenSumberDayaManusiaTeoridanAplikasi, Bandung: Alfabeta, 2016.

J. Winardi, MotivasiPemotivasianDalamManajemen, (Jakarta: RajawaliPers, 2011.

Julyansyah Noor, MetodologiPenelitianSkripsi, Tesis, Disertasi\&KaryaIlmiah, Jakarta: KencanaPrenada Media Group, 2013.

$\begin{array}{llll}\text { Kenneth N. Wexlydan Gary } & \text { Nuki, }\end{array}$

PerilakuOrganisasidanPsikologiPersonalia, Jakarta: RinekaCipta,2003.

QuraishShihab, Tafsir Al- MishbahPesandankesan Al-Qur'an,Jakarta: LenteraHati, 2002.

Malayu S.P Hasibuan, ManajemenSumberDayaManusia,Jakarta: Bumi Aksara, 2005 .

MuchdarsyahSinungan, ProduktivitasApa Dan Bagaimana,Jakarta: BumiAksara, 2008 .

MudrajatKuncoro, MetodeRisetuntukBisnisdanEkonomiJakarta :Erlangga, 2009.

Muhammad Firdaus, EkonometrikaSuatuPendekatanAplikatif,Jakarta : PT BumiAksara, 2011. 
Muhammad QuraishShihab, Tafsir Al- Mishbah,Jakarta: LenteraHati, 2002. ProfilPuskesmasMarancarUdikKabupatenTapanuli Selatan.

SadiliSamsudin, ManajemenSumberDayaManusia, Bandung:CV PustakaSetia, 2006.

SaifuddinAzwar, MetodePenelitian,Yogyakarta: PustakaPelajar, 2004.

Sondang P. Siagian, ManajemenSumberdayaManusia, (Jakarta :BumiAksara, 2007.

Stephen P. Robbins dan Timothy A. Judge, PerilakuOrganisasi,Jakarta :SalembaEmpat, 2008.

Sugiyono, MetodePenelitianBisnisBandung :Afabeta, 2012.

Sugiyono, MetodePenelitianKuantitatif (pendekatankuantitatif, kualitatif, dan $R \&$, Bandung :Alfabeta, 2013.

SuharsimiArikunto, ProsedurPenelitianSuatupendekatanPraktek, Jakarta: RinekaCipta, 2008.

SuharsimiArikunto, ProsedurPenelitianSuatuPendekatanPraktikJakarta: PT.RinekaCipta, 2002.

Swatno\&DonniJuniPriansa, Manjaemen SDM dalamOrganisasiPublikdanBisnis, Bandung :Alfabeta, 2013. 